\title{
Myocardial protection: The efficacy of an ultra-short- acting $\beta$-blocker, esmolol, as a cardioplegic agent
}

Ryuzo Bessho, MD

David J. Chambers, PhD
From the Cardiac Surgical Research/ Cardiothoracic Surgery, The Rayne Institute, Guy's and St Thomas' NHS Trust, St Thomas' Hospital, London, United Kingdom.

Dr Ryuzo Bessho was a visiting research fellow from the Division of Cardiovascular Surgery, the Department of Surgery II, Nippon Medical School, Tokyo, Japan.

Received for publication Oct 10, 2000; revisions requested Nov 30, 2000; revisions received March 12, 2001; accepted for publication March 19, 2001.

Address for reprints: David J. Chambers, $\mathrm{PhD}$, Cardiac Surgical Research/Cardiothoracic Surgery, The Rayne Institute, Guy's and St Thomas' NHS Trust, St Thomas' Hospital, London SE1 7EH, United Kingdom (E-mail: david.chambers@kcl.ac.uk).

J Thorac Cardiovasc Surg 2001;122:9931003

Copyright (C) 2001 by The American Association for Thoracic Surgery

$0022-5223 / 2001 \$ 35.00+0 \quad \mathbf{1 2 / 1 / 1 1 5 9 1 9}$

doi:10.1067/mtc.2001.115919
Objective: During myocardial revascularization, some surgeons (particularly in the United Kingdom) use intermittent crossclamping with fibrillation as an alternative to cardioplegia. We recently showed that intermittent crossclamping with fibrillation has an intrinsic protection equivalent to that of cardioplegia. In this study we hypothesized that arrest, rather than fibrillation, during intermittent crossclamping may be beneficial. Because esmolol, an ultra-short-acting $\beta$-blocker, is known to attenuate myocardial ischemia-reperfusion injury, we compared the protective effect of esmolol arrest with that of intermittent crossclamping with fibrillation and conventional cardioplegia (St Thomas' Hospital solution).

Methods: Isolated rat hearts were Langendorff perfused at either constant flow (14 $\mathrm{mL} / \mathrm{min}$ ) or constant pressure $(75 \mathrm{~mm} \mathrm{Hg}$ ) with oxygenated Krebs-Henseleit bicarbonate buffer $\left(37^{\circ} \mathrm{C}\right)$, and left ventricular developed pressure was assessed. In study 1 (constant flow perfusion) 8 groups ( $n=6$ hearts per group) were studied: (1) 40 minutes of global ischemia; (2) 2 minutes of St Thomas' Hospital infusion and 40 minutes of ischemia; (3) multidose (every 10 minutes) infusions of St Thomas' Hospital solution during 40 minutes of ischemia; (4) 2 minutes of esmolol infusion and 40 minutes of ischemia; (5) multidose (every 10 minutes) esmolol infusions during 40 minutes of ischemia; (6) continuous infusion of esmolol for 40 minutes during coronary perfusion; (7) intermittent $(4 \times 10$ minutes) ischemia with ventricular fibrillation; and $(8)$ intermittent $(4 \times 10$ minutes) ischemia preceded by intermittent esmolol administration. All protocols were followed by 60 minutes of reperfusion. Further experiments (study 2) examined the esmolol administration method in hearts perfused by constant pressure.

Results: An optimal arresting dose of $1.0 \mathrm{mmol} / \mathrm{L}$ esmolol was established. In study 1 recovery of left ventricular developed pressure (expressed as percentage of preischemic value) was $7 \% \pm 4 \%, 28 \% \pm 8 \%, 70 \% \pm 5 \%, 8 \% \pm 1 \%, 90 \% \pm 4 \%, 65 \%$ $\pm 3 \%, 71 \% \pm 5 \%$, and $76 \% \pm 5 \%$ in groups 1 to 8 , respectively. Intermittent esmolol arrest with global ischemia provided equivalent myocardial protection to intermittent crossclamping with fibrillation, continuous esmolol perfusion, and multidose $\mathrm{St}$ Thomas' Hospital solution. Surprisingly, multidose esmolol infusion was more protective than all other treatments. In further experiments (study 2) optimal recovery was obtained with multiple esmolol infusions (by constant flow or constant pressure), but continuous esmolol infusion (at constant flow) was less effective than constant pressure infusion.

Conclusions: Intermittent arrest with esmolol did not enhance protection of intermittent crossclamping with fibrillation; however, multiple esmolol infusions during global ischemia provided improved protection. Administration (constant flow or constant pressure) of arresting solutions influenced outcome only during continuous infusion. Multidose esmolol arrest may be a beneficial alternative to intermittent crossclamping with fibrillation or conventional cardioplegia. 


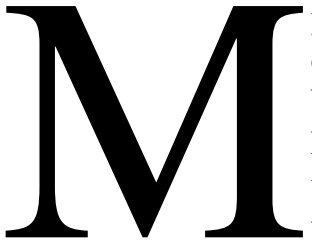

yocardial protection during cardiac operations is most commonly achieved by hyperkalemic cardioplegic arrest ${ }^{1,2}$; however, a minority of surgeons, particularly in the United Kingdom, continue to favor the technique of intermittent ventricular fibrillation (VF), either with ${ }^{3}$ or without ${ }^{4}$ aortic crossclamping. Recent clinical studies ${ }^{5,6}$ have shown that intermittent crossclamp (ventricular) fibrillation (ICCF) provides equivalent myocardial protection to cold cardioplegia. In these studies, however, the cumulative ischemic duration during ICCF was invariably shorter than that of the comparative ischemia associated with cardioplegic arrest; hence, it was unclear whether this shorter ischemic duration was associated with reduced injury. $\mathrm{We}^{7}$ have recently demonstrated, in an experimental study, that intermittent global ischemia either alone or with VF does provide an intrinsic protection. In addition, VF did not appear to exacerbate any ischemic injury. This suggested the possibility that rapid arrest with a cardioplegic agent, rather than ischemic arrest or VF (ICCF), might further improve myocardial protection.

It is known that $\beta$-adrenergic antagonists ( $\beta$-blockers) attenuate the extent of myocardial injury during ischemia and reperfusion. ${ }^{8,9}$ The negative inotropic and chronotropic effects of these drugs is thought to concomitantly reduce myocardial oxygen consumption, decrease sympathetic tone, reduce myocardial substrate use, and stabilize cell membranes, ${ }^{10,11}$ thereby exerting a beneficial effect on ischemic myocardium. Most $\beta$-blockers, however, have prolonged negative inotropic properties, ${ }^{12}$ with a half-life of many hours, which limits their use during cardiac operations. In contrast, the ultra-short-acting and cardioselective $\beta$-blocker esmolol has a half-life of a few minutes, ${ }^{13}$ which allows its negative inotropic effects to be abolished rapidly after reduction or cessation of infusion. This short half-life of esmolol led Sweeney and Frazier ${ }^{14}$ to use high-dose esmolol infusion in hearts of patients with compromised left ventricular (LV) function who were supported by an LV assist device to suppress cardiac inotropy and chronotropy during myocardial revascularization. Subsequently, experimental $^{15,16}$ and clinical ${ }^{17-20}$ studies have shown that esmolol can be used to obtain minimal myocardial contraction during cardiac operations while maintaining continuous normothermic coronary perfusion to avoid ischemia. With this technique, myocardial protection was equivalent to or better than that obtained with cold crystalloid or blood cardioplegia.

Therefore, we hypothesized that a combination of esmolol arrest with intermittent global ischemia would enhance the protection observed with ICCF, and we conducted a study to examine the protective effect of intermittent esmolol arrest and to compare this effect with ICCF and conventional cardioplegic solutions. As a consequence of this, a further study was conducted to examine the optimal method for infusion of the protective solutions.

\section{Materials and Methods \\ Animals}

Adult male Wistar rats (240-300 g body weight) were used (Bantin and Kingman, Hull, United Kingdom). All animals received humane care in accordance with the "Guidance on the Operation of the Animals (Scientific Procedures) Act of 1986" published by Her Majesty's Stationery Office (London, England). Rats were anesthetized with $95 \%$ oxygen $/ 5 \%$ carbon dioxide bubbled through diethyl ether and were then anticoagulated with heparin (1000 IU/kg body weight) administered intravenously.

\section{Heart Isolation and Perfusion}

Hearts were rapidly excised from the anesthetized rats and immersed in cold $\left(4^{\circ} \mathrm{C}\right)$ Krebs-Henseleit buffer (KHB). The aorta was then cannulated, and the heart was perfused at $37^{\circ} \mathrm{C}$ in the Langendorff mode, as previously described. ${ }^{7}$ Hearts were perfused at either constant pressure $(75 \mathrm{~mm} \mathrm{Hg}$ ) or constant flow (14 $\mathrm{mL} / \mathrm{min}$ ) by means of a peristaltic pump (Gilson Minipuls 3; Gilson Company, Inc, Lewis Center, Ohio). A unipolar electrocardiogram (ECG) was obtained through a silver electrode inserted into the free wall of the left ventricle and a reference electrode connected to the aortic cannula; the ECG was continuously recorded throughout the protocol. All hearts were subjected to an equilibration period (20 minutes) of aerobic perfusion, and baseline readings of LV systolic pressure (in millimeters of mercury), LV enddiastolic pressure (LVEDP; in millimeters of mercury), heart rate (in beats per minute), and coronary flow (in milliliters per minute) were taken. LV developed pressure (LVDP) was calculated as the LV systolic pressure minus LVEDP. Coronary flow was measured by timed collections of the coronary effluent. The development of contracture during ischemia (when of sufficient duration) was recorded. Infusion volume of cardioplegic solution was measured by collecting coronary effluent during infusion of cardioplegic solution.

\section{Exclusion Criteria}

Hearts not satisfying preassigned exclusion criteria at the time of the baseline readings were excluded from the study. The acceptable ranges for LVDP, heart rate, and coronary flow were as follows: greater than $100 \mathrm{~mm} \mathrm{Hg}$, greater than 220 beats/min, and 8 to $16 \mathrm{~mL} / \mathrm{min}$, respectively.

\section{Perfusion Medium}

This was a modified $\mathrm{KHB}$ with the following composition: $\mathrm{NaCl}$, $118.5 \mathrm{mmol} / \mathrm{L} ; \mathrm{NaHCO}_{3}, 25.0 \mathrm{mmol} / \mathrm{L} ; \mathrm{KCl}, 4.8 \mathrm{mmol} / \mathrm{L} ; \mathrm{MgSO}_{4}$, $1.2 \mathrm{mmol} / \mathrm{L} ; \mathrm{CaCl}_{2}, 1.4 \mathrm{mmol} / \mathrm{L}$; and glucose, $11.0 \mathrm{mmol} / \mathrm{L}$. The buffer was prepared daily, filtered through a $5-\mu \mathrm{m}$ pore size cellulose nitrate membrane filter before use, and continuously gassed with $95 \%$ oxygen $/ 5 \%$ carbon dioxide mixture to give a $\mathrm{pH}$ of 7.4 at $37^{\circ} \mathrm{C}$.

\section{Preparation and Administration of Esmolol and Cardioplegic Solution}

Esmolol (Brevibloc; Baxter Pharmaceuticals, Crowthorne, Berkshire, United Kingdom) was provided in vials containing 10 $\mathrm{mL}$ of a $250 \mathrm{mg} / \mathrm{mL}$ solution. Preliminary studies were carried out to determine a dose-response curve for esmolol; 5 dilutions of the original esmolol solution $(1: 3,1: 10,1: 30,1: 100$, and 1:300 diluted in oxygenated $\mathrm{KHB}$ ) were infused with an electronic syringe 
pump (Razel Scientific Instruments Inc, Stamford, Conn) attached to a multiway aortic cannula at an infusion rate of $0.215 \mathrm{~mL} / \mathrm{min}$. Hearts were perfused at a constant flow rate of $14 \mathrm{~mL} / \mathrm{min}$; consequently, the final concentrations of esmolol reaching the heart were approximately $3.0,1.0,0.3,0.1$, and $0.03 \mathrm{mmol} / \mathrm{L}$, respectively. As a result of these dose-response studies, subsequent esmolol cardioplegic solution was prepared by diluting $1.5 \mathrm{~mL}$ of esmolol (250 $\mathrm{mg} / \mathrm{mL}$ ) in $1000 \mathrm{~mL}$ of oxygenated $\mathrm{KHB}$, giving a final esmolol concentration of $1.0 \mathrm{mmol} / \mathrm{L}$.

The St Thomas' Hospital cardioplegic solution No. 2 (STH2) was prepared daily with the following composition: $\mathrm{NaCl}, 110.0$ $\mathrm{mmol} / \mathrm{L} ; \mathrm{MgCl}_{2} \cdot 6 \mathrm{H}_{2} \mathrm{O}, 16.0 \mathrm{mmol} / \mathrm{L} ; \mathrm{KCl}, 16.0 \mathrm{mmol} / \mathrm{L} ; \mathrm{CaCl}_{2}$. $2 \mathrm{H}_{2} \mathrm{O}, 1.2 \mathrm{mmol} / \mathrm{L}$; and $\mathrm{NaHCO}_{3}, 10.0 \mathrm{mmol} / \mathrm{L}$. The $\mathrm{pH}$ was adjusted to 7.8 at $37^{\circ} \mathrm{C}$, and the solution was filtered through a 5$\mu \mathrm{m}$ cellulose nitrate filter before use.

Each solution was delivered at $37^{\circ} \mathrm{C}$ and at either a constant pressure of $45 \mathrm{~mm} \mathrm{Hg}$ or a constant flow rate of $14 \mathrm{~mL} / \mathrm{min}$ for 2 minutes each infusion.

\section{Induction and Termination of VF}

VF was induced with an electrical fibrillator (model G570, Department of Bioengineering, St Thomas' Hospital) by passing alternating current through 2 silicone-coated silver electrodes, one attached to the apex of the ventricle and the other grounded on the aortic cannula. The minimum voltage necessary to achieve an alternating current that maintained VF was used. If VF occurred during reperfusion or did not terminate spontaneously after the fibrillator was turned off, it was terminated by the use of a defibrillator (model G 434, Department of Bioengineering, St Thomas' Hospital).

\section{Preliminary Study: Determination of Dose-Response Curve for Esmolol}

Before starting the following protocols, we determined the doseresponse curve for esmolol. Hearts were randomly assigned to one of 5 esmolol concentration groups (ie, 0.03, 0.1, 0.3, 1.0, and 3.0 $\mathrm{mmol} / \mathrm{L} ; \mathrm{n}=6$ hearts per group). Each concentration of esmolol was continuously delivered to the heart for 10 minutes, and function (LVDP) and ECG characteristics (atrial and ventricular rate) were measured and compared with initial values (expressed as percentage of aerobic function).

\section{Perfusion Protocol}

After 20 minutes of aerobic equilibration perfusion, hearts were subjected to 1 of 2 perfusion protocols, as shown in Figure 1. During the ischemic periods, hearts were immersed in $\mathrm{KHB}$ at $37^{\circ} \mathrm{C}$ with the use of a temperature-controlled, water-jacketed heart chamber.

Study 1: Myocardial protection with esmolol arrest compared with STH2 cardioplegia or ICCF. All hearts were perfused at a constant flow rate of $14 \mathrm{~mL} / \mathrm{min}$ throughout the protocol and were randomly assigned to 1 of 8 groups, as listed in Table $1(n=6$ hearts per group). All protocols were followed by a further $60 \mathrm{~min}-$ utes of reperfusion, when recovery of myocardial function was measured.

Study 2: Does the method of cardioplegic infusion (constant flow vs constant pressure) influence protection? In study 1 (above) all hearts were perfused throughout by means of constant flow, which is a relatively nonphysiologic perfusion technique and may have affected recovery of function. Consequently, it was decided to perfuse hearts at constant pressure during aerobic perfusion and reperfusion and to determine whether constant flow or constant pressure infusion influenced protection.

Thus, all hearts were perfused at a constant perfusion pressure equivalent to $75 \mathrm{~mm} \mathrm{Hg}$ both before and after global ischemia and randomized to 1 of 8 groups as listed in Table $2(n=6$ hearts per group). All protocols were followed by a further 60 minutes of reperfusion, when recovery of myocardial function was measured.

\section{Expression of Results}

Postischemic recovery of LVDP, heart rate, and coronary flow were expressed as a percentage of the baseline values; LVEDP was expressed as an absolute value (in millimeters of mercury). The following measurements related to contracture during ischemia were also noted: (1) time to onset of contracture (in minutes); (2) time to peak contracture (in minutes); and (3) magnitude of peak contracture (in millimeters of mercury). In addition, we measured the time to the cessation of mechanical activity (in seconds).

\section{Statistics}

Statistical analysis was performed with StatView and SuperANOVA programs (Abacus Concepts Inc, Berkeley, Calif) on an Apple Macintosh computer (Apple Computer, Cupertino, Calif). All data are reported as means \pm standard error of the mean. Comparison between groups was assessed with 1-way analysis of variance with post hoc analysis by the Fisher protected least significant difference test, which allowed for multiple comparisons. The Student $t$ test (or the Mann-Whitney test when appropriate) was used to compare 2 means.

\section{Results \\ Preliminary Study: Determination of Dose-Response Curve for Esmolol}

The esmolol dose-response curve for LVDP, ventricular rate, and atrial rate (expressed as percentage of initial values) is shown in Figure 2. Each index demonstrated a negative sigmoidal curve with increasing concentrations of esmolol. LVDP and ventricular rate were zero at an esmolol concentration of $1 \mathrm{mmol} / \mathrm{L}$, whereas atrial rate did not reach zero until a concentration of $3 \mathrm{mmol} / \mathrm{L}$.

\section{Study 1: Myocardial Protection With Esmolol Arrest Compared With STH2 Cardioplegia or ICCF}

The mean baseline values of LVDP, LVEDP, and heart rate at the end of 20 minutes of aerobic perfusion in groups 1 to 8 are shown in Table 3. The differences between groups could be due to chance $(P>.02)$.

\section{Recovery of function}

LVDP AND HEART RATE. The changes in recovery of LVDP over 60 minutes of reperfusion are shown in Figure 3. Hearts subjected to 40 minutes of ischemic arrest (group 1) showed little recovery, as did hearts subjected to a single 2-minute esmolol infusion (group 4). Surprisingly, hearts 


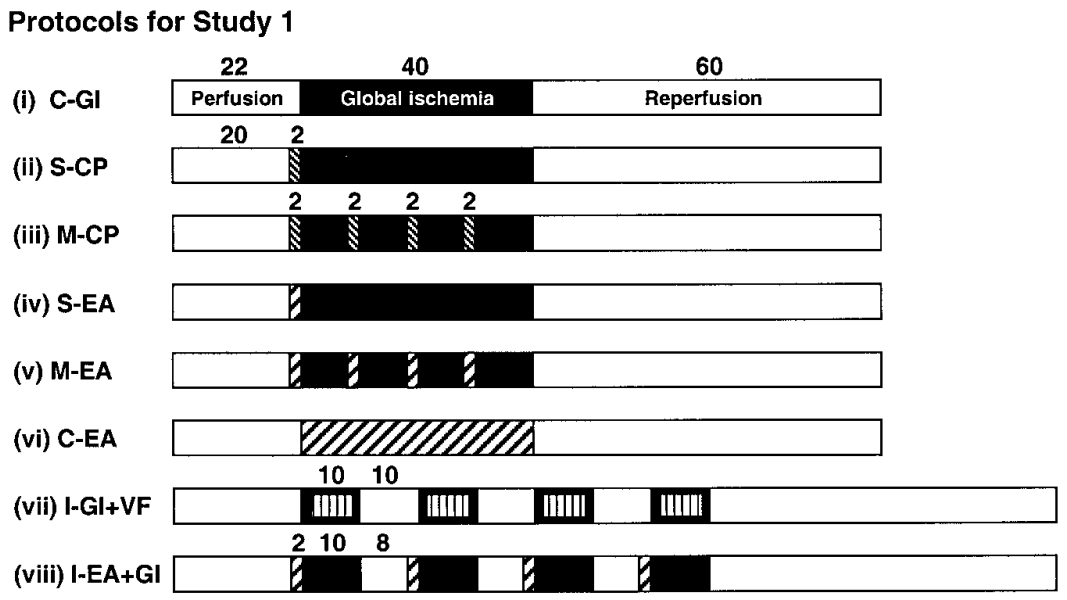

Protocols for Study 2

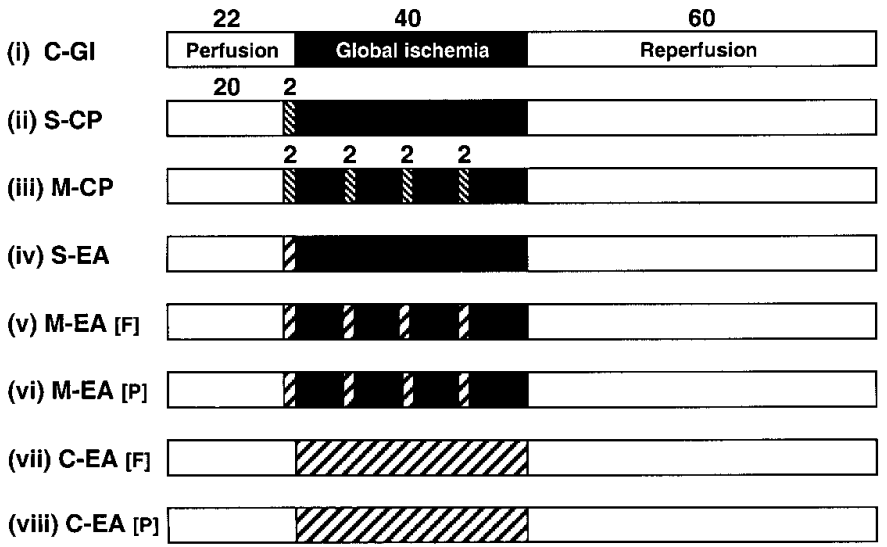

STH2 infusion Aerobic perfusion IIII Global ischemia with esmolol with VF

Figure 1. Experimental perfusion protocols. Study 1, All hearts were perfused at a constant flow rate of $14 \mathrm{~mL} / \mathrm{min}$ throughout the protocol and were randomly assigned to 1 of 8 groups, as listed in Table $\mathbf{1}$ ( $\mathbf{n}=\mathbf{6}$ hearts per group). Study 2, All hearts were perfused at a constant perfusion pressure equivalent to $75 \mathrm{~mm} \mathrm{Hg}$ both before and after global ischemia and randomized to 1 of 8 groups, as listed in Table 2 ( $n=6$ hearts per group). All protocols were followed by 60 minutes of reperfusion, when recovery of myocardial function was measured.

subjected to a single 2-minute STH2 infusion (group 2) only recovered very slowly and to a low value, but the value was significantly higher than those for groups 1 and 4 (see Appendix Table 1). Hearts from other groups recovered more rapidly and to relatively high values, reaching a plateau around 10 to 15 minutes after onset of reperfusion; however, hearts subjected to 40 minutes of continuous esmolol infusion (group 6) did not reach a plateau of recovery until 40 minutes of reperfusion. The highest and most rapid recovery was observed in hearts subjected to multiple esmolol infusions (group 5), and this was significantly higher than in all other groups. Interestingly, hearts from groups
3 and 6 to 8 recovered to similar values by 60 minutes of reperfusion, and thus esmolol infusion before intermittent global ischemia was equally as protective as ICCF, multiple infusion of STH2, and continuous infusion of esmolol during coronary perfusion.

The percentage recovery of heart rate after 60 minutes of reperfusion was similar in all groups (not shown).

LVEDP. Changes in postischemic LVEDP during 60 minutes of reperfusion are shown in Figure 4. At the onset of reperfusion, LVEDP values were moderately elevated, although continuous coronary perfusion (at $14 \mathrm{~mL} / \mathrm{min}$ ) of esmolol cardioplegic solution caused an LVEDP of $109 \mathrm{~mm}$ 
TABLE 1. Study 1: Groups into which the hearts were randomly assigned

\begin{tabular}{ll}
\hline Group & \multicolumn{1}{c}{ Description } \\
\hline 1. C-GI & Continuous global ischemia for 40 minutes \\
2. S-CP & Single-dose (2 minutes) STH2 infused before 40 minutes of continuous global ischemia \\
3. M-CP & Multidose (2 minutes) STH2 infused before and every 10 minutes during 40 minutes of global ischemia \\
4. S-EA & Single-dose (2 minutes) esmolol cardioplegia (1 mmol/L esmolol in KHB) infused before 40 minutes of continuous global \\
& ischemia \\
5. M-EA & Multidose (2 minutes) esmolol cardioplegia (1 mmol/L) infused before and every 10 minutes during 40 minutes of global \\
& ischemia \\
6. C-EA & Continuous coronary perfusion of esmolol cardioplegic solution for 40 minutes (1 mmol/L) \\
7. I-GI+VF & $4 \times 10$-minute intermittent episodes of global ischemia with VF and 10 minutes of reperfusion in sinus rhythm \\
8. I-EA+GI & $4 \times 10$-minute intermittent episodes of global ischemia preceded by 2-minute infusions of esmolol cardioplegic solution \\
& $(1$ mmol/L) and followed by 8 minutes of reperfusion
\end{tabular}

STH2, St Thomas' Hospital solution No. 2; KHB, Krebs-Henseleit buffer. All protocols were followed by a further 60 minutes of reperfusion, when recovery of myocardial function was measured.

TABLE 2. Study 2: Groups into which the hearts were randomly assigned

\begin{tabular}{|c|c|}
\hline Group & Description \\
\hline 1. C-GI & Continuous global ischemia for 40 minutes \\
\hline 2. S-CP & Single-dose (2 minutes) STH2 infused (at $45 \mathrm{~mm} \mathrm{Hg}$ ) before 40 minutes of continuous global ischemia \\
\hline 3. M-CP & Multidose (2 minutes) STH2 infused (at $45 \mathrm{~mm} \mathrm{Hg}$ ) before and every 10 minutes during 40 minutes of global ischemia \\
\hline 4. S-EA & $\begin{array}{l}\text { Single-dose ( } 2 \text { minutes) esmolol cardioplegic solution ( } 1 \mathrm{mmol} / \mathrm{L} \text { in } \mathrm{KHB} \text { ) infused (at } 14 \mathrm{~mL} / \mathrm{min} \text { ) before } 40 \text { minutes of } \\
\text { continuous global ischemia }\end{array}$ \\
\hline 5. M-EA[F] & $\begin{array}{l}\text { Multidose ( } 2 \text { minutes) esmolol cardioplegic solution }(1 \mathrm{mmol} / \mathrm{L} \text { ) infused (at } 14 \mathrm{~mL} / \mathrm{min} \text { ) before and every } 10 \text { minutes } \\
\text { during } 40 \text { minutes of global ischemia }\end{array}$ \\
\hline 6. M-EA[P] & $\begin{array}{l}\text { Multidose ( } 2 \text { minutes) esmolol cardioplegic solution (1 } \mathrm{mmol} / \mathrm{L} \text { ) infused (at } 45 \mathrm{~mm} \mathrm{Hg} \text { ) before and every } 10 \text { minutes } \\
\text { during } 40 \text { minutes of global ischemia }\end{array}$ \\
\hline 7. C-EA[F] & Continuous coronary perfusion for 40 minutes (at $14 \mathrm{~mL} / \mathrm{min}$ ) of esmolol cardioplegic solution (1 mmol/L) \\
\hline 8. $C-E A[P]$ & Continuous coronary perfusion for 40 minutes (at $45 \mathrm{~mm} \mathrm{Hg}$ ) of esmolol cardioplegic solution (1 mmol/L) \\
\hline
\end{tabular}

STH2, St Thomas' Hospital solution No. 2; KHB, Krebs-Henseleit buffer. All protocols were followed by a further 60 minutes of reperfusion, when recovery of myocardial function was measured.

$\mathrm{Hg}$. Interestingly, poor LVDP recovery (groups 1, 2, and 4) was associated with rapid and maintained increases in LVEDP on reperfusion. In contrast, in groups 3 and 5 to 8, LVEDP declined to relatively normal levels, mirroring the good recovery in LVDP (Figure 3).

\section{Study 2: Does the Method of Cardioplegic Infusion (Constant Flow vs Constant Pressure) Influence Protection?}

The mean baseline values of LVDP, coronary flow, LVEDP, and heart rate after 20 minutes of aerobic perfusion in groups 1 to 8 are shown in Table 4; the differences between groups could be due to chance $(P>.02)$. The mean time for cessation of mechanical activity (in seconds) is also presented in Table 4 for each group. Hearts subjected to global ischemia alone (group 1) had significantly prolonged mechanical activity compared with all other groups; mechanical quiescence was most rapid in the $\mathrm{STH} 2$ groups.
In addition, the mean total volumes of cardioplegic solution delivered to the heart in the single-dose, multidose, and continuous groups are shown in Table 4.

\section{Recovery of function}

LVDP, CORONARY FLOW, AND HEART RATE. The changes in LVDP over 60 minutes of reperfusion are shown in Figure $5, A$. It is of interest that in hearts subjected to equivalent protocols in both study 1 and study 2 (groups 1-5), recovery was more rapid and reached a higher level in study 2 , when aerobic perfusion and reperfusion at constant pressure was used, indicating an adverse effect of constant flow perfusion. However, hearts subjected to multidose esmolol infusion at constant flow (group 8) recovered to around $100 \%$ in both study 1 and study 2 . Complete protection (around $100 \%$ ) was also observed in hearts subjected to multidose infusions at a constant pressure of either STH2 or esmolol cardioplegic solution in study 2 ; however, protection with continuous infusion of esmolol cardioplegia at a constant 


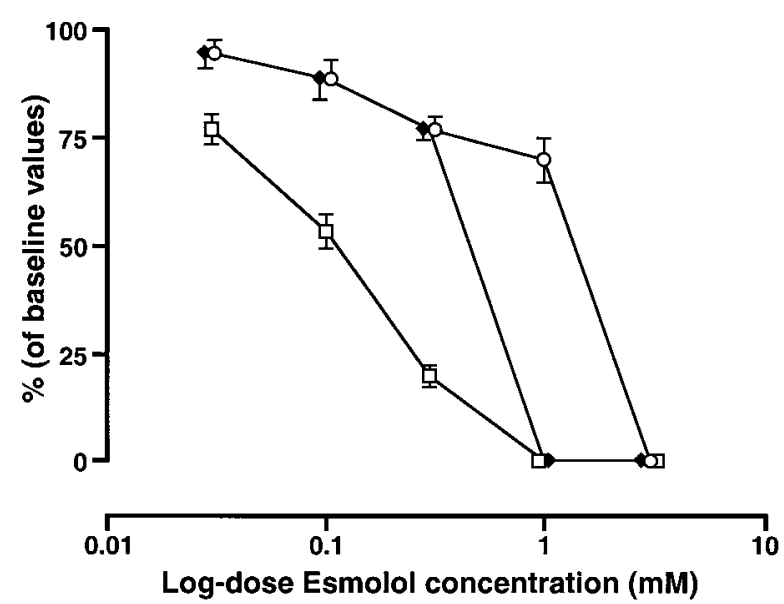

Figure 2. Log dose-response curves for LVDP (open squares), ventricular rate (closed diamonds), and atrial rate (open circles), with increasing concentrations $(0.03-3.0 \mathrm{mmol} / \mathrm{L}$ ) of esmolol in KHB as a percentage of the baseline value.

flow was significantly lower than when esmolol was continuously infused at constant pressure (see Appendix Table 2).

The recovery profile of coronary flow also shows some interesting differences between groups (Figure 5, B). In particular, hearts subjected to multiple infusions of STH2 exhibited a hyperemic peak (to $40 \%$ ) at 5 minutes, with subsequent decline. In contrast, coronary flow in hearts subjected to multiple infusions of esmolol (infused either by means of constant pressure or constant flow) recovered to supranormal levels, which increased throughout the $60 \mathrm{~min}-$ utes of reperfusion, reaching significantly higher levels than all other groups.

The percentage recovery of heart rate was similar in all groups, reaching approximately $100 \%$ of baseline values (data not shown).

LVEDP. Changes in postischemic LVEDP during 60 minutes of reperfusion are shown in Figure 6; these changes were similar to those seen in study 1 . In general, LVEDP values mirrored those of LVDP, in which those hearts that recovered well showed a relatively low value of LVEDP during reperfusion, whereas hearts that recovered poorly (with a low LVDP) had a higher LVEDP (groups 1, 2, and 4).

ISCHEMIC CONTRACTURE. Ischemic contracture occurred only in groups 1,2 , and 4 . Time to onset and time to peak of contracture were significantly delayed by either STH2 or esmolol infusions compared with global ischemia alone $(P<.001)$. In addition, peak contracture was significantly $(P<.01)$ higher in group 1 than in groups 2 and 4.

\section{Discussion}

The present study has demonstrated the following: (1) the ultra-short-acting $\beta$-blocker esmolol induces complete

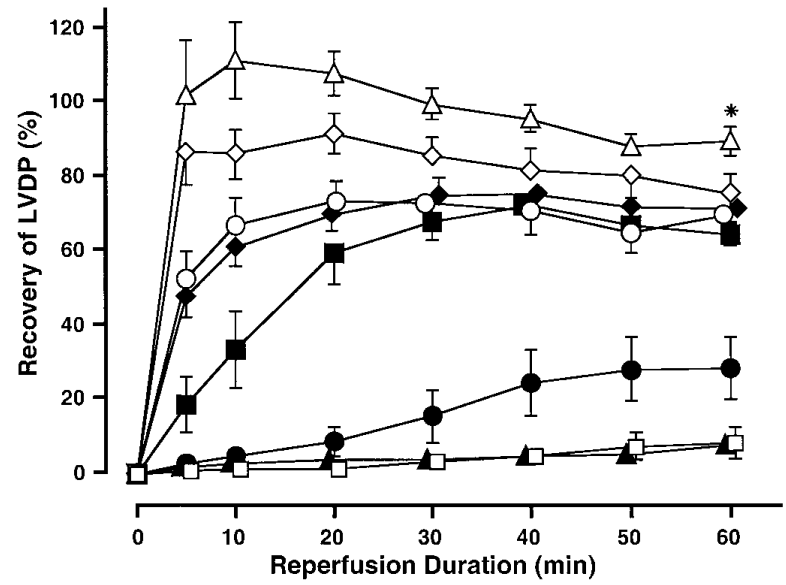

Figure 3. Recovery of LVDP (expressed as percentage of the preischemic control value) during $\mathbf{6 0}$ minutes of reperfusion. Values from 6 hearts per group are given as means \pm standard error of the mean. ${ }^{*} P=.048$ versus other groups. Open squares, C-GI; filled circles, S-CP; open circles, M-CP; filled triangles, S-EA; open triangles, M-EA; filled squares, C-EA; filled diamonds, I-GI+VF; open diamonds, I-EA+GI. Abbreviations are as for Figure 1, study 1.

mechanical and ventricular arrest at a concentration of 1 $\mathrm{mmol} / \mathrm{L}$; (2) intermittent esmolol arrest did not enhance the protection achieved with ICCF; (3) our previous findings that ICCF was equally as protective as multidose cardioplegia can be supported; (4) multidose esmolol arrest was significantly more protective than that with other solutions (at least when hearts were perfused at constant flow); (5) the method of infusion (constant flow or constant pressure) was not an influence on recovery for multidose esmolol infusion (at this ischemic duration) but had a significant effect on continuous esmolol infusion; and (6) constant flow during perfusion-reperfusion had a generally detrimental effect.

In the United Kingdom a significant number of surgeons use ICCF to induce cardiac surgical conditions that allow coronary revascularization during coronary artery bypass operations ${ }^{3}$; this technique was shown to produce good myocardial protection in recent clinical trials. ${ }^{5,6}$ However, because it was unclear from these studies whether ICCF was itself protective or whether the similar protection to that achieved with cardioplegia was due to the shorter ischemic durations (and hence less ischemic injury) associated with ICCF, our previous study ${ }^{7}$ was the first (to our knowledge) to demonstrate that ICCF exerted an intrinsic protection that was equivalent to that of multidose cardioplegia when the total ischemic duration was the same. For the present study, we hypothesized that arrest, rather than VF, during the intermittent crossclamp periods might further enhance the protective effect of this technique, and we therefore examined whether the ultra-short-acting $\beta$-blocker esmolol might have a role in this situation. 


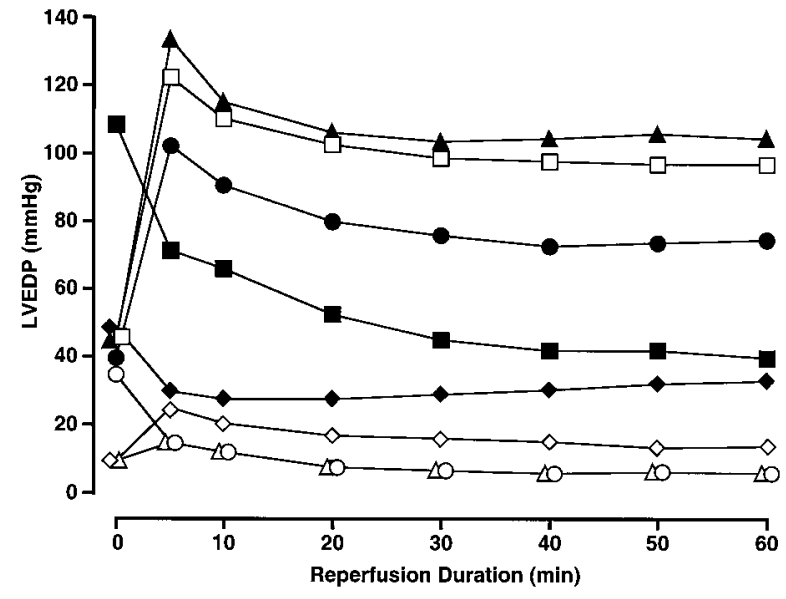

Figure 4. Changes in LVEDP during reperfusion (expressed as absolute value in millimeters of mercury). Values from 6 hearts per group are given as means \pm standard error of the mean. Symbols and abbreviations are as in Figure 3.

\section{$\beta$-Blockers and Myocardial Protection}

The mechanism of action of $\beta$-blockers is widely known ${ }^{21}$; they antagonize the binding of catecholamines to the $\beta$ adrenergic receptors of the cell membrane complex, indirectly reducing the number of activated calcium channels and hence cellular calcium influx. This results in a decrease in heart rate and myocardial contractility. Although $\beta$-blockers have been demonstrated to exert a protective effect in the setting of ischemia in both clinical and experimental studies, the mechanism by which this is achieved is incompletely understood. Catecholamine depletion has been shown to improve recovery of isolated hearts after ischemia, ${ }^{22}$ and part of the cardioprotective effect of $\beta$-blockers probably derives from their antagonism to the unfavorable effects of catecholamines in ischemia; however, several other theories have been suggested. ${ }^{23,24}$

Most $\beta$-blockers have prolonged negative inotropic effects that last for hours, ${ }^{12}$ which renders them unsuitable for use during acute situations, such as cardiac operations. However, esmolol, a cardioselective $\beta$-adrenergic blocker, has an extremely short duration of action (half-life of about 9 minutes), ${ }^{13}$ which is attributable to rapid enzymatic hydrolysis by blood and tissue esterases, ${ }^{25}$ making esmolol a potential candidate for myocardial protection during operations. Indeed, esmolol was first used to improve myocardial protection during cardiac operations in $1992 .{ }^{14}$ Subsequently, a number of experimental ${ }^{15,16,26}$ and clini$\mathrm{cal}^{17,19,20,27}$ studies have demonstrated the efficacy of using esmolol-enriched blood to induce minimal myocardial contraction with a flaccid heart, thereby generating conditions suitable for coronary artery operations while maintaining coronary perfusion. This use of esmolol was shown to reduce myocardial edema formation and result in either
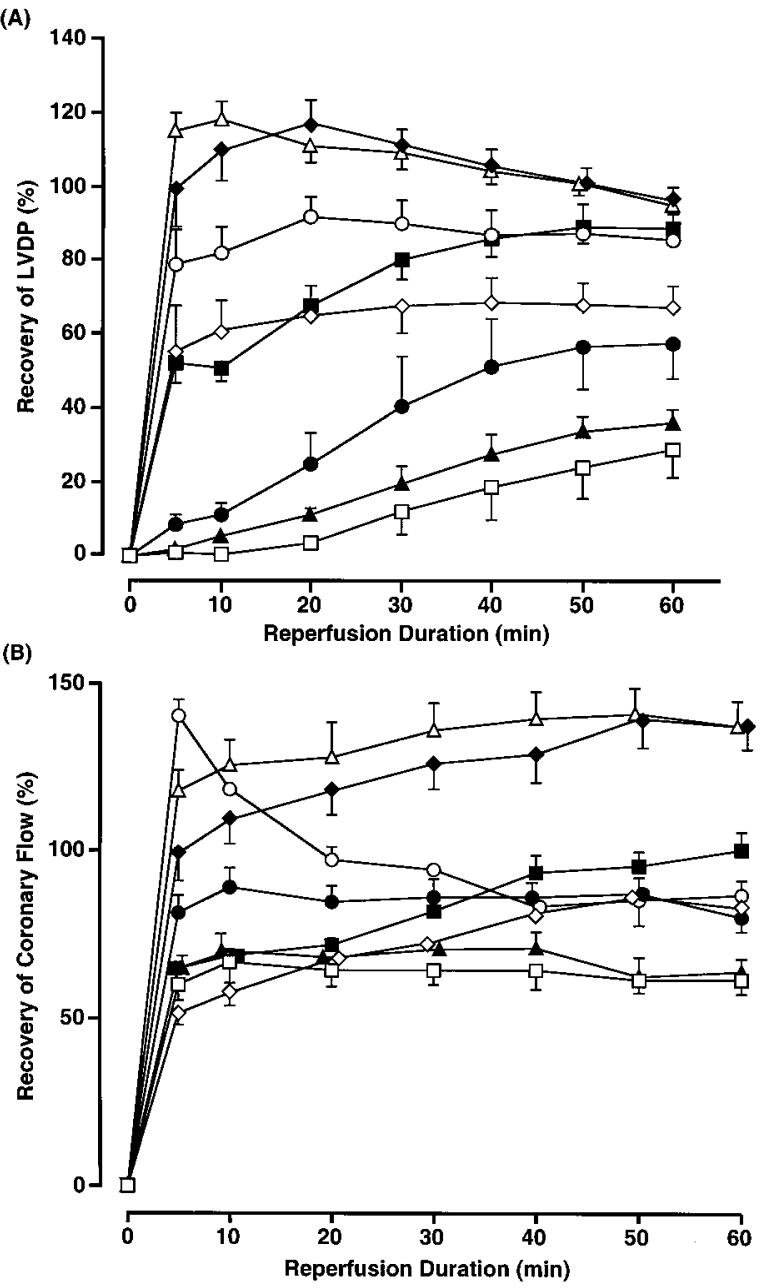

Figure 5. Recovery of LVP (A) and coronary flow (B; expressed as percentage of the preischemic control value) during 60 minutes of reperfusion. Values from 6 hearts per group are given as means \pm standard error of the mean. Open squares, C-Gl; filled circles, S$\mathrm{CP}$; open circles, M-CP; filled triangles, S-EA; open triangles, $\mathrm{M}$ EA[F]; filled diamonds, M-EA[P]; open diamonds, C-EA[F]; filled squares, C-EA[P]. Abbreviations are as for Figure 1, study 2.

equivalent or improved myocardial protection when compared with intermittent cold crystalloid cardioplegia, ${ }^{16,19,27}$ intermittent cold blood cardioplegia, ${ }^{20}$ or warm continuous blood cardioplegia. ${ }^{15,26}$

Esmolol has previously been shown to induce ventricular arrest when used at high concentrations. Ede and colleagues ${ }^{28}$ arrested rat hearts at a dose of $1.36 \mathrm{mmol} / \mathrm{L}$. Pirk and coworkers ${ }^{29}$ demonstrated that $250 \mathrm{mg} / \mathrm{L}$ esmolol (approximately $0.7 \mathrm{mmol} / \mathrm{L}$ ) was an optimal concentration for arrest of the rat heart, whereas $500 \mathrm{mg} / \mathrm{L}$ (approximately $1.4 \mathrm{mmol} / \mathrm{L}$ ) resulted in reduced recovery of cardiac function (when washed out). In the present study we observed similar effects, with an optimal arrest dose of $1.0 \mathrm{mmol} / \mathrm{L}$; a 
TABLE 3. Baseline values (measured after 20 minutes of aerobic perfusion to achieve equilibration) of LVDP, heart rate, and LVEDP

\begin{tabular}{lcccccccc}
\hline & $\begin{array}{c}\text { C-GI } \\
\text { (group 1) }\end{array}$ & $\begin{array}{c}\text { S-CP } \\
\text { (group 2) }\end{array}$ & $\begin{array}{c}\text { M-CP } \\
\text { (group 3) }\end{array}$ & $\begin{array}{c}\text { S-EA } \\
\text { (group 4) }\end{array}$ & $\begin{array}{c}\text { M-EA } \\
\text { (group 5) }\end{array}$ & $\begin{array}{c}\text { C-EA } \\
\text { (group 6) }\end{array}$ & $\begin{array}{c}\text { I-GI+VF } \\
\text { (group 7) }\end{array}$ & $\begin{array}{c}\text { I-EA+GI } \\
\text { (group 8) }\end{array}$ \\
\hline LVDP (mm Hg) & $132 \pm 10$ & $117 \pm 4$ & $130 \pm 14$ & $139 \pm 11$ & $128 \pm 10$ & $114 \pm 6$ & $122 \pm 3$ & $124 \pm 5$ \\
Heart rate (beats/min) & $289 \pm 9$ & $286 \pm 5$ & $288 \pm 12$ & $269 \pm 13$ & $253 \pm 7$ & $274 \pm 7$ & $279 \pm 13$ & $274 \pm 19$ \\
LVEDP (mm Hg) & $4.0 \pm 1.0$ & $4.7 \pm 1.3$ & $4.2 \pm 1.7$ & $3.3 \pm 0.5$ & $4.5 \pm 1.2$ & $5.8 \pm 2.1$ & $4.0 \pm 1.5$ & $4.7 \pm 1.9$ \\
\hline
\end{tabular}

The differences between groups could be due to chance $(P>$.2). For definition of abbreviations, see text and Table 1.

TABLE 4. Baseline values (measured after 20 minutes of aerobic perfusion to achieve equilibration) of LVDP, coronary flow, heart rate, and LVEDP

\begin{tabular}{|c|c|c|c|c|c|c|c|c|}
\hline & $\begin{array}{c}\text { C-GI } \\
\text { (group 1) }\end{array}$ & $\begin{array}{c}\text { S-CP } \\
\text { (group 2) }\end{array}$ & $\begin{array}{c}\text { M-CP } \\
\text { (group 3) }\end{array}$ & $\begin{array}{c}\text { S-EA } \\
\text { (group 4) }\end{array}$ & $\begin{array}{l}\text { M-EA[F] } \\
\text { (group 5) }\end{array}$ & $\begin{array}{l}\text { M-EA[P] } \\
\text { (group 6) }\end{array}$ & $\begin{array}{l}\text { C-EA[F] } \\
\text { (group 7) }\end{array}$ & $\begin{array}{c}\text { C-EA[P] } \\
\text { (group 8) }\end{array}$ \\
\hline LVDP (mm Hg) & $121 \pm 8$ & $107 \pm 2$ & $133 \pm 9$ & $124 \pm 9$ & $131 \pm 10$ & $107 \pm 4$ & $136 \pm 13$ & $114 \pm 5$ \\
\hline Coronary flow (mL/min) & $11.3 \pm 0.7$ & $12.8 \pm 1.8$ & $11.9 \pm 0.4$ & $12.4 \pm 0.8$ & $11.4 \pm 0.7$ & $9.8 \pm 0.6$ & $12.2 \pm 0.8$ & $9.9 \pm 0.3$ \\
\hline Heart rate (beats/min) & $256 \pm 13$ & $247 \pm 8$ & $242 \pm 11$ & $272 \pm 13$ & $272 \pm 11$ & $276 \pm 11$ & $263 \pm 7$ & $257 \pm 9$ \\
\hline $\operatorname{LVEDP}(\mathrm{mm} \mathrm{Hg})$ & $4.7 \pm 1.3$ & $5.8 \pm 1.4$ & $4.7 \pm 0.6$ & $4.3 \pm 0.6$ & $5.3 \pm 0.5$ & $6.5 \pm 0.6$ & $4.3 \pm 0.3$ & $7.5 \pm 0.7$ \\
\hline Time to mechanical arrest (s) & $222 \pm 23$ & $35 \pm 4^{*} \dagger$ & $31 \pm 3^{*} \dagger$ & $47 \pm 3^{*}$ & $55 \pm 2^{*}$ & $57 \pm 2^{*}$ & $59 \pm 6^{*}$ & $52 \pm 3^{*}$ \\
\hline Total infusion volume (mL) & - & $16.3 \pm 0.1$ & $61.5 \pm 0.4$ & $28.0 \pm 0.0$ & $112.0 \pm 0.0$ & $42.7 \pm 3.0$ & $560.0 \pm 0.0$ & $121.7 \pm 3.3$ \\
\hline
\end{tabular}

The differences between groups could be due to chance $(P>.02)$. For definition of abbreviations, see text and Table 2 .

${ }^{*} P<.001$ versus group 1 .

$\dagger P<.01$ versus groups 4 to 8 .

higher dose $(3.0 \mathrm{mmol} / \mathrm{L})$ was required for atrial arrest but led to ventricular dysfunction on washout.

\section{Cardioplegic Infusion Regimen: Effects of Single-Dose, Multidose, or Continuous Infusion}

Multidose cardioplegic infusion enhances protection compared with single-dose infusion, ${ }^{30,31}$ and this was confirmed in the present study with both STH2 and esmolol arrest. This additional benefit has been related to many factors, including washout of metabolites (eg, lactate, protons, and inorganic phosphate) that inhibit anaerobic metabolism, replacement of substrate (particularly oxygen with blood cardioplegia or the oxygenated KHB with esmolol in the present study), and limits an evolving edema. Accumulation of metabolic intermediates cause further disturbances of energy metabolism, ionic homeostasis, and intracellular $\mathrm{pH}$ regulation ${ }^{32}$ and eventually leads to loss of cellular viability. Recently, ${ }^{33}$ multiple STH2 infusions were shown to maintain intracellular sodium $\left(\mathrm{Na}^{+}{ }_{\mathrm{i}}\right)$ concentrations during ischemia and reperfusion in rat hearts, whereas a single STH infusion only delayed (and slightly reduced) the rise in $\mathrm{Na}_{\mathrm{i}}$ in unprotected hearts. Interestingly, $\mathrm{Na}_{\mathrm{i}}$ levels correlated with recovery of function, which were of a similar order to those observed in the present study. It is tempting to speculate that similar effects on ionic homeostasis may be occurring in our study with the multiple infusions of esmolol car- dioplegic solution, particularly in view of the suggested lidocaine-like activity (sodium-channel blocking effect) of esmolol at high doses. ${ }^{28}$ The efficacy of myocardial protection with $\beta$-blockers may require multiple infusion. It has been demonstrated ${ }^{34}$ that acute $\beta$-blockade was only effective during relatively short ischemic periods, and this would be supported by the present data. The short biologic half-life of esmolol ${ }^{25}$ would also implicate the importance of multiple reinfusions.

There is increasing use of continuous (blood) cardioplegia, which avoids additional ischemia and is particularly useful for patients with severe ischemic disease for which further ischemic trauma is likely to be detrimental. Logically, avoidance of ischemia should provide optimal myocardial protection. However, previous experimental studies ${ }^{15,16}$ with continuous esmolol infusion demonstrated that full protection was only provided for a finite duration, and extended infusions resulted in depressed function. This is supported by the present study: hearts receiving continuous esmolol had a lower recovery than hearts subjected to global ischemia with multidose esmolol infusions. It is feasible that total esmolol dose may influence outcome ${ }^{16}$ and that the relatively high dose may exert an adverse effect when infused over long periods. ${ }^{29}$ Our preliminary dose-response studies also showed adverse effects with a higher esmolol dose $(3.0 \mathrm{mmol} / \mathrm{L})$, 
and it is possible that continuous infusion with the lower dose $(1.0 \mathrm{mmol} / \mathrm{L})$ may have had similar effects. It is also known that esmolol increases coronary vascular resistance, with high doses inducing vasoconstriction. We confirmed this in the present study with our observation that coronary vascular resistance increased during continuous esmolol infusion at constant flow, and infusion volume decreased throughout continuous esmolol infusion at constant pressure (data not shown).

\section{Effect of Constant Flow or Constant Pressure Perfusion-Infusion}

In study 1 all hearts were perfused and reperfused at constant flow, and all cardioplegic solutions were infused at the same constant flow. It has previously been shown ${ }^{35-37}$ that postischemic perfusion pressure (or flow rate) plays an important role in myocardial protection, particularly during the initial reperfusion period, during which reduced flow rate (compared with the preischemia period) was shown ${ }^{37}$ to enhance postischemic recovery of function. Hearts in study 2 were perfused and reperfused by the more physiologic method of constant pressure, and effects of administering cardioplegic solutions by constant flow or constant pressure were investigated. The results supported the previous findings ${ }^{35-37}$ that reperfusion pressure is an important component of protection. Equivalent groups of hearts had higher recovery than that in study 1 . Also of interest was our finding that continuous infusion of esmolol cardioplegic solution at constant flow resulted in depressed recovery of function (Figure 5), an effect that is likely to be related to increased coronary vascular resistance (see above).

\section{Limitations of the Study}

We concede that the present studies were conducted in rat hearts perfused with a crystalloid solution rather than blood and that this is a relatively unphysiologic situation. We are aware that esmolol is metabolized by esterases, ${ }^{25}$ and consequently, this study would fail to reveal any interaction between the metabolism of esmolol and the cardioprotective efficacy of esmolol.

It is also possible that esmolol may have adverse systemic effects that would not be revealed in our study; this would require investigation in the intact animal. Previous studies ${ }^{14,19,20,27}$ have used esmolol clinically during relatively long-term continuous infusion (albeit at lower concentrations) with no report of any systemic adverse effects. Hence, we would speculate that use of short, multiple, highdose infusions is unlikely to have major systemic effects, although this would need verification.

Myocardial ischemic disease is a multifactorial process; there is a spectrum of injury that affects the method of myocardial protection. Hearts used in this study were taken from normal rats, and it is likely that any protective effect of

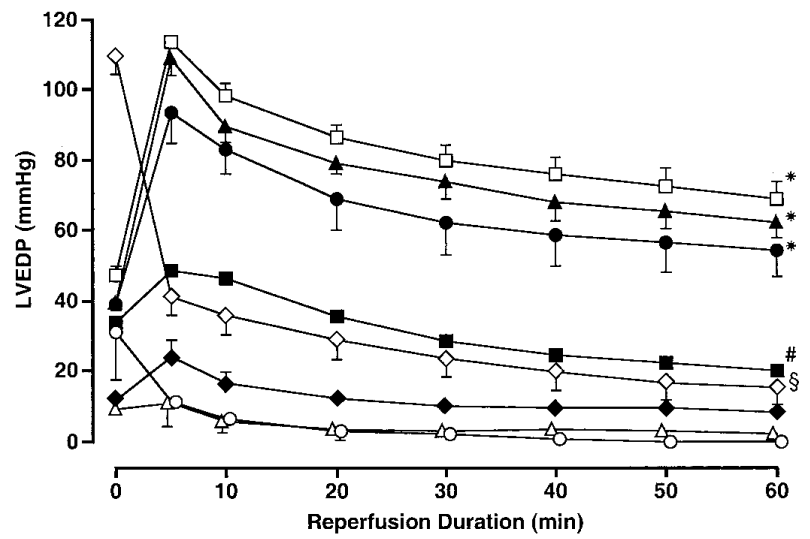

Figure 6. Changes in LVEDP (expressed as absolute value in millimeters of mercury) during $\mathbf{6 0}$ minutes of reperfusion. Values from 6 hearts per group are given as means \pm standard error of the mean. ${ }^{*} P<.001$ versus groups 3 and 5 to $8 ; \# P=.0013$ and $P=.0037$ versus groups 3 and 5 , respectively; $\S P=.011$ and $P=.026$ versus groups 3 and 5, respectively. Symbols and abbreviations are as in Figure 5.

esmolol would be different in jeopardized hearts with ischemic injury or disease. In addition, any such hearts are likely to require prolonged periods of ischemia to correct the lesion, and the ischemic duration described in this study is relatively short. Further studies are warranted to investigate these aspects of myocardial protection with esmolol cardioplegic solution.

\section{Conclusion}

Esmolol arrest, rather than VF, during intermittent crossclamping did not enhance the myocardial protection of this technique. Interestingly, however, we observed that multidose esmolol infusions during global ischemia provided complete protection, and this protection was not influenced by the method of administration. The method of administration of esmolol cardioplegic solution was important, however, during continuous esmolol infusion. The use of esmolol as a cardioplegic agent may be a beneficial alternative to conventional cardioplegia or ICCF and would be applicable to all types of cardiac operations.

\section{References}

1. Robinson LA, Schwarz GD, Goddard DB, Fleming WH, Galbraith TA. Myocardial protection for acquired heart disease surgery: results of a national survey. Ann Thorac Surg. 1995;59:361-72.

2. Caputo M, Ascione R, Angelini GD, Suleiman MS, Bryan AJ. The end of the cold era: from intermittent cold to intermittent warm blood cardioplegia. Eur J Cardiothorac Surg. 1998;14:467-75.

3. Bonchek LI, Burlingame MW, Vazales BE, Lundy EF, Gassmann CJ. Applicability of noncardioplegic coronary bypass to high-risk patients. Selection of patients, technique, and clinical experience in 3000 patients. J Thorac Cardiovasc Surg. 1992;103:230-7.

4. Akins CW. 1987: Early and late results following emergency isolated 
myocardial revascularization during hypothermic fibrillatory arrest. Updated in 1994 by Cary W. Akins, MD. Ann Thorac Surg. 1994;58:1205-6.

5. Musumeci F, Feccia M, MacCarthy PA, Ellis GR, Mammana L, Brinn $\mathrm{F}$, et al. Prospective randomized trial of single clamp technique versus intermittent ischaemic arrest: myocardial and neurological outcome. Eur J Cardiothorac Surg. 1998;13:702-9.

6. Liu Z, Valencia O, Treasure T, Murday AJ. Cold blood cardioplegia or intermittent cross-clamping in coronary artery bypass grafting? Ann Thorac Surg. 1998;66:462-5.

7. Bessho R, Chambers DJ. Experimental study of intermittent crossclamping with fibrillation and myocardial protection: reduced injury from shorter cumulative ischemia or intrinsic protective effect? $J$ Thorac Cardiovasc Surg. 2000;120:528-37.

8. Magee PG, Gardner TJ, Flaherty JT, Bulkley BH, Goldman RA, Gott VL. Improved myocardial protection with propranolol during induced ischemia. Circulation. 1980;62(Suppl):I-49-56.

9. Khandoudi N, Percevault-Albadine J, Bril A. Comparative effects of carvedilol and metoprolol on cardiac ischemia-reperfusion injury. $J$ Cardiovasc Pharmacol. 1998;32:443-51.

10. Nies AS, Shand DG. Clinical pharmacology of propranolol. Circulation. 1975;52:6-15.

11. Kloner RA, Kirshenbaum J, Lange R, Antman EM, Braunwald E. Experimental and clinical observations on the efficacy of esmolol in myocardial ischemia. Am J Cardiol. 1985;56:40F-8F.

12. Wolman RL, Fiedler MA. Esmolol and beta-adrenergic blockade. AANA J. 1991;59:541-8.

13. Gorczynski RJ. Basic pharmacology of esmolol. Am J Cardiol. 1985;56:3F-13F.

14. Sweeney MS, Frazier OH. Device-supported myocardial revascularization: safe help for sick hearts. Ann Thorac Surg. 1992;54:1065-70.

15. Mehlhorn U, Allen SJ, Adams DL, Davis KL, Gogola GR, Warters RD. Cardiac surgical conditions induced by beta-blockade: effect on myocardial fluid balance. Ann Thorac Surg. 1996;62:143-50.

16. Warters RD, Allen SJ, Davis KL, Geissler HJ, Bischoff I, Mutschler E, et al. Beta-blockade as an alternative to cardioplegic arrest during cardiopulmonary bypass. Ann Thorac Surg. 1998;65:961-6.

17. Matsuda H, Fukushima N, Kadoba K, Sawa Y, Nomura F, Kume Y, et al. Application of ultra short acting beta blockade (esmolol) in pediatric open heart surgery: a trial in total anomalous pulmonary venous return. J Card Surg. 1996;11:411-6.

18. Mehlhorn U, Sudkamp M. Beta-blockade as an alternative to cardioplegia. Thorac Cardiovasc Surg. 1998;46(Suppl 2):302-7.

19. Mehlhorn U, Sauer H, Kuhn-Regnier F, Sudkamp M, Dhein S, Eberhardt F, et al. Myocardial beta-blockade as an alternative to cardioplegic arrest during coronary artery surgery. Cardiovasc Surg. 1999;7:549-57.

20. Kuhn-Regnier F, Natour E, Dhein S, Dapunt O, Geissler HJ, LaRose $\mathrm{K}$, et al. Beta-blockade versus Buckberg blood-cardioplegia in coronary bypass operation. Eur J Cardiothorac Surg. 1999;15:67-74.

21. Goodman J, Gilman J. Pharmacological basis of therapeutics. 9th ed. New York: McGraw-Hill; 1995.
22. Gauduel Y, Karagueuzian HS, de Leiris J. Deleterious effects of endogenous catecholamines on hypoxic myocardial cells following reoxygenation. J Mol Cell Cardiol. 1979;11:717-31.

23. Nakazawa M, Katano Y, Imai S, Matsushita K, Ohuchi M. Effects of L- and D-propranolol on the ischemic myocardial metabolism of the isolated guniea pig heart, as studied by 31P-NMR. J Cardiovasc Pharmacol. 1982;4:700-4.

24. Nagai S, Miyazaki Y, Ogawa K, Satake T, Sugiyama S, Ozawa T. The effects of beta-blocking agents on mitochondrial function in ischemic myocardium. Jpn Circ J. 1984;48:32-6.

25. Quon CY, Stampfli HF. Biochemical properties of blood esmolol esterase. Drug Metab Dispos. 1985;13:420-4.

26. Geissler HJ, Davis KL, Laine GA, Ostrin EJ, Mehlhorn U, Hekmat K, et al. Myocardial protection with high-dose beta-blockade in acute myocardial ischemia. Eur J Cardiothorac Surg. 2000;17:63-70.

27. Hekmat K, Clemens RM, Mehlhorn U, Geissler HJ, Kuhn-Regnier F, de Vivie ER. Emergency coronary artery surgery after failed PTCA: myocardial protection with continuous coronary perfusion of betablocker-enriched blood. Thorac Cardiovasc Surg. 1998;46:333-8.

28. Ede M, Ye J, Gregorash L, Summers R, Pargaonkar S, LeHouerou D, et al. Beyond hyperkalemia: beta-blocker-induced cardiac arrest for normothermic cardiac operations. Ann Thorac Surg. 1997;63:721-7.

29. Pirk J, Kolar F, Ost'adal B, Sedivy J, Stambergova A, Kellovsky P. The effect of the ultrashort beta-blocker esmolol on cardiac function recovery: an experimental study. Eur J Cardiothorac Surg. 1999;15:199-203.

30. Engelman RM, Auvil J, O'Donoghue MJ, Levitsky S. The significance of multidose cardioplegia and hypothermia in myocardial preservation during ischemic arrest. J Thorac Cardiovasc Surg. 1978;75:555-63.

31. Lucas SK, Elmer EB, Flaherty JT, Prodromos CC, Bulkley BH, Gott BL, et al. Effect of multiple-dose potassium cardioplegia on myocardial ischemia, return of ventricular function, and ultrastructural preservation. J Thorac Cardiovasc Surg. 1980;80:102-10.

32. Rovetto MJ, Lamberton WF, Neely JR. Mechanisms of glycolytic inhibition in ischemic rat hearts. Circ Res. 1975;37:742-51.

33. Schepkin VD, Choy IO, Budinger TF, Young JN, DeCampli WM. Multi-dose crystalloid cardioplegia preserves intracellular sodium homeostasis in myocardium. J Mol Cell Cardiol. 1999;31:1643-51.

34. Toleikis PM, Tomlinson CW. Myocardial functional preservation during ischemia: influence of beta blocking agents. Mol Cell Biochem. 1997;176:205-10.

35. Okamoto F, Allen BS, Buckberg GD, Bugyi H, Leaf J. Reperfusion conditions: importance of ensuring gentle versus sudden reperfusion during relief of coronary occlusion. $J$ Thorac Cardiovasc Surg. 1986;92:613-20.

36. Hori M, Kitakaze M, Sato H, Takashima S, Iwakura K, Inoue M, et al. Staged reperfusion attenuates myocardial stunning in dogs. Role of transient acidosis during early reperfusion. Circulation. 1991;84:2135-45.

37. Takeo S, Liu JX, Tanonaka K, Nasa Y, Yabe K, Tanahashi H, et al. Reperfusion at reduced flow rates enhances postischemic contractile recovery of perfused heart. Am J Physiol. 1995;268:H2384-95. 
APPENDIX TABLE 1. Results of post hoc analysis for recovery of LVDP after $\mathbf{6 0}$ minutes of reperfusion for study 1

\begin{tabular}{lcccccccc}
\hline & $\begin{array}{c}\text { C-GI } \\
\text { (group 1) }\end{array}$ & $\begin{array}{c}\text { S-CP } \\
\text { (group 2) }\end{array}$ & $\begin{array}{c}\text { M-CP } \\
\text { (group 3) }\end{array}$ & $\begin{array}{c}\text { S-EA } \\
\text { (group 4) }\end{array}$ & $\begin{array}{c}\text { M-EA } \\
\text { (group 5) }\end{array}$ & $\begin{array}{c}\text { C-EA } \\
\text { (group 6) }\end{array}$ & $\begin{array}{c}\text { I-GI+VF } \\
\text { (group 7) }\end{array}$ & $\begin{array}{c}\text { I-EA+GI } \\
\text { (group 8) }\end{array}$ \\
\hline C-GI (group 1) & - & .0057 & $<.0001$ & .9132 & $<.0001$ & $<.0001$ & $<.0001$ \\
S-CP (group 2) & .0057 & - & $<.0001$ & .0076 & $<.0001$ & $<.0001$ & $<.0001$ & $<.0001$ \\
M-CP (group 3) & $<.0001$ & $<.0001$ & - & $<.0001$ & .0099 & .4545 & .8842 & .4562 \\
S-EA (group 4) & .9132 & .0076 & $<.0001$ & - & $<.0001$ & $<.0001$ & $<.0001$ & $<.0001$ \\
M-EA (group 5) & $<.0001$ & $<.0001$ & .0099 & $<.0001$ & - & .0012 & .0143 \\
C-EA (group 6) & $<.0001$ & $<.0001$ & .4545 & $<.0001$ & .0012 & - & .04724 \\
I-GI+VF (group 7) & $<.0001$ & $<.0001$ & .8842 & $<.0001$ & .0143 & .3724 & -.139 \\
I-EA+GI (group 8) & $<.0001$ & $<.0001$ & .4562 & $<.0001$ & .0484 & .139 & .5481 & .5481 \\
\hline
\end{tabular}

For definition of abbreviations, see Table 1.

APPENDIX TABLE 2. Results of post hoc analysis for recovery of LVDP after 60 minutes of reperfusion for study 2

\begin{tabular}{lcccccccc}
\hline & $\begin{array}{c}\text { C-GI } \\
\text { (group 1) }\end{array}$ & $\begin{array}{c}\text { S-CP } \\
\text { (group 2) }\end{array}$ & $\begin{array}{c}\text { M-CP } \\
\text { (group 3) }\end{array}$ & $\begin{array}{c}\text { S-EA } \\
\text { (group 4) }\end{array}$ & $\begin{array}{r}\text { M-EA[F] } \\
\text { (group 5) }\end{array}$ & $\begin{array}{c}\text { M-EA[P] } \\
\text { (group 6) }\end{array}$ & $\begin{array}{c}\text { C-EA[F] } \\
\text { (group 7) }\end{array}$ & $\begin{array}{c}\text { C-EA[P] } \\
\text { (group 8) }\end{array}$ \\
\hline C-GI (group 1) & - & .0011 & $<.0001$ & .3847 & $<.0001$ & $<.0001$ & $<.0001$ \\
S-CP (group 2) & .0011 & - & .0013 & .0116 & $<.0001$ & $<.0001$ & .2401 \\
M-CP (group 3) & $<.0001$ & .0013 & - & $<.0001$ & .2618 & .1990 & .0288 & .7395 \\
S-EA (group 4) & .3847 & .0116 & $<.0001$ & - & $<.0001$ & $<.0001$ & .0004 \\
M-EA[F] (group 5) & $<.0001$ & $<.0001$ & .2618 & $<.0001$ & - & .8676 & .0015 \\
M-EA[P] (group 6) & $<.0001$ & $<.0001$ & .1990 & $<.0001$ & .8676 & - & .0009 \\
C-EA[F] (group 7) & $<.0001$ & .2401 & .0288 & .0004 & .0015 & .0009 & -.4265 \\
C-EA[P] (group 8) & $<.0001$ & .0005 & .7395 & $<.0001$ & .4265 & .3373 & .0129 & .0129 \\
\hline
\end{tabular}

For definitions of abbreviations, see Table 2. 